\title{
Urinary metal concentrations among female welders
}

\author{
Victoria H. Arrandale, Jeremy Beach, George S. Cembrowski, and \\ Nicola M. Cherry
}

Version Post-Print/Accepted Manuscript

Citation Arrandale VH, Beach J, Cembrowski GS, Cherry NM. Urinary metal (published version) concentrations among female welders. Ann Occup Hyg. 2015 Jan;59(1):52-61. PMID 25359273.

Publisher's Statement This is a pre-copyedited, author-produced PDF of an article accepted for publication in the Annals of Occupational Hygiene following peer review. The version of record Ann Occup Hyg (2015) 59 (1): 52-61 is available online at: https://dx.doi.org/10.1093/annhyg/meu079.

\section{How to cite TSpace items}

Always cite the published version, so the author(s) will receive recognition through services that track citation counts, e.g. Scopus. If you need to cite the page number of the TSpace version (original manuscript or accepted manuscript) because you cannot access the published version, then cite the TSpace version in addition to the published version using the permanent URI (handle) found on the record page. 
TITLE: Urinary metal concentrations among female welders

AUTHORS: V. H. Arrandale ${ }^{1,2,3}$, J. Beach $^{1}$, G. S. Cembrowski ${ }^{4}$, N. M. Cherry ${ }^{1}$

1 Division of Preventive Medicine, University of Alberta, Edmonton, CANADA

2 Occupational Cancer Care Ontario, Cancer Care Ontario, Toronto, CANADA

3 Dalla Lana School of Public Health, University of Toronto, Toronto, CANADA

4 Division of Medical Biochemistry, University of Alberta, Edmonton, CANADA

Word count: 3608

Key words: Metal exposure, occupation, welding, female, biomarkers of exposure 
ABSTRACT (word count: 334)

As part of a Canada-wide study of women entering non-traditional trades (Women's Health in Apprenticeship Trades - Metalworkers and Electricians (WHAT-ME)), we examined spot urine samples from women welders in Alberta to determine whether urinary metal concentrations exceeded those of the general population, to compare levels to previously published urinary concentrations in male welders and to examine the relationship with welding tasks. Women mailed-in urine samples collected close to the time of completing a detailed exposure questionnaire, including welding tasks on their most recent day welding at work. Of 53 welders working in their trade, 45 had urinary creatinine $>0.3-\leq 3.0 \mathrm{~g} / \mathrm{L}$ and were included in analyses. Seven metals were examined for which both population and male welder urinary concentrations were available: cadmium, chromium, cobalt, copper, manganese, nickel and zinc. Principal component analysis was used to extract 3 components from natural log transformed creatininecorrected metal concentrations. Of the 45 women, 17 reported more than one main task. Overall two thirds worked in fabrication, a third on pipe welding and smaller numbers on repair, in construction or other tasks: manual metal arc welding was reported by $62 \%$, semi-automatic arc welding by $47 \%$ and arc welding with a tungsten electrode by $15 \%$. In multiple regression analyses little relation was found between urinary metals and task or type of welding, except for cadmium where lower levels were seen in those reporting semi-automatic manual welding (after adjustment for age and smoking). The proportion of women welders exceeding the selected general population 95th percentile was high for manganese (96\%) and chromium (29\%). Urinary metal concentrations were similar to those reported for male welders with only manganese, with a geometric mean in women of $1.91 \mathrm{ug} / \mathrm{g}$ creatinine, and perhaps copper (11.8 ug/g creatinine), consistently lower in male welders. Although not evident from the task analysis reported here, 
differences in exposure by sex may be explained by type of welding or by other work practices. A closely comparable cohort of male welders would be necessary to examine this hypothesis more fully. 


\section{INTRODUCTION}

In Canada women are increasingly entering trades that have traditionally been pursued only by men. In 2011 there were over 1000 women in Canada registered as welding apprentices, representing $6.0 \%$ of welding apprentices overall (Statistics Canada, 2013). Though women are still a small minority, their representation has grown steadily since 1991 (the earliest year for which data are publically available) when women made up less than $1 \%$ of registered welding apprentices in the country (Statistics Canada, 2013).

Welders are exposed to a number of potentially hazardous workplace agents of which the most relevant to the current report are inhaled metal fume and dust. Previous studies reporting on biomarkers of metal exposure in welding have focused almost exclusively on men (Weiss et al., 2013; Ellingsen et al., 2006; Mukherjee et al., 2004; Scheepers et al., 2008). In those few studies in which women welders were included, the women were a minority and no stratified analyses were reported (Li et al., 2004), or the occupational environment was atypical (e.g., jewelry welders (Trevisan et al., 1994)).

Women differ from men in many ways that may be relevant to bio-marker exposure assessment, including physiology (i.e., absorption, distribution, metabolism and excretion of xenobiotics), and behavior (e.g., risk tolerance). A lack of research on exposures in women in welding and other non-traditional trades means that there is very little, if any, evidence of whether women in these trades have the same exposures as men, or whether the health risks are the same (apart from possible effects on the fetus). The WHAT-ME study (Women's Health in Apprenticeship Trades - Metalworkers and Electricians) was set up in Alberta in 2011 and has become a prospective cohort including every province and territory in Canada. During the first months of 
the study we collected urine samples from women welders in Alberta to examine the feasibility of this approach for identifying tasks and practices that might be associated with risk to women and their unborn child. We wanted to know how metal concentrations among female welders compared with concentrations published for the general population and for male welders. For this we concentrated on seven metals (cadmium, chromium, cobalt, copper, manganese, nickel and zinc) for which we could find published data for both sets of comparisons (Weiss et al., 2013; Ellingsen et al., 2006; Scheepers et al., 2008; US Centres for Disease Control and Prevention, 2013, Health Canada, 2010; Paschal et al., 1998; Mukherjee et al., 2004; Verschoor et al., 1988; Luo et al., 2009). We were conscious that ACGIH published urinary biological exposures indices (BEI) for only three of these (cadmium, chromium and cobalt) (American Conference of Governmental Industrial Hygienists (ACGIH), 2012) and that for the others urinary concentrations might, at best, be a useful indicator at the group level (Lauwerys and Hoet, 2001). With these reservations in mind, we examined whether any welding task was associated with high concentrations of urinary metals to identify possible areas for intervention.

\section{METHODS}

The WHAT-ME study is a Canadian prospective cohort study of women who have been registered at some time since 2005 as an apprentice in Canada in one of the trades of interest: welder, boiler maker, steam fitter/pipe fitter (all considered 'welding' trades), or electrician (residential, commercial or industrial). Women in these trades were identified through the provincial apprenticeship bodies, which sent eligible women recruitment packages on our behalf. After signing a written consent form, subjects completed a baseline questionnaire either by 
telephone or online. The baseline questionnaire included information on personal health history, previous pregnancies and a complete job history. At six month intervals thereafter, participants completed a further questionnaire concentrating particularly on trade-specific exposures.

Between October 2011 and September 2012 all Alberta participants completing their first (six month) exposure questionnaire were asked to provide a urine sample. This was mailed to the University of Alberta for analysis. The WHAT-ME study protocol was reviewed and approved by the University of Alberta Research Ethics Board (REB).

\section{Exposure}

Very detailed information on welding is being collected at each contact including type of welding and welding task; for each welding task subjects are asked to recall all of the base metals, rods/wires, flux, shielding gas and metal coatings involved. This information will be collected up to ten times per subject and will be used in the final analysis of health effects in the complete cohort of 400 welders across Canada. For the current analysis of early recruits in a single province, only reported welding tasks and type of welding on the most recent day of welding are considered. Tasks included welding (shielded metal arc welding/manual metal arc welding (SMAW); gas metal arc welding/metal inert gas/semi-automatic arc welding with gas shield (GMAW); gas tungsten arc welding/tungsten inert gas (GTAW); plasma arc welding (PAW); submerged arc welding (SAW); other) as well as non-welding tasks (pipe welding, fabrication, repair, construction, mixed, other).

\section{Biological Sample Collection}


Following a previously piloted procedure (Cherry et al., 2011), participants were mailed a urine collection kit which included a sterile sample collection vial and return packaging. Samples received at the University of Alberta were shaken vigorously and split into three equal samples. Samples were frozen in $15 \mathrm{~mL}$ polypropylene screw top vial (\#60-732, Sarstedt Inc.) in a $-80^{\circ} \mathrm{C}$ freezer prior to laboratory analysis. Samples were analyzed at the University of Alberta Hospital by ICP-MS (PerkinElmer NexION 300) for the seven metals discussed here: cadmium, chromium, cobalt, copper, manganese, nickel, and zinc. In addition, results were obtained for aluminum, antimony, arsenic, barium, beryllium, bismuth, mercury, lead, selenium and thallium. Samples were analyzed for creatinine concentration by the Beckman Jaffe method. Samples with a creatinine concentration $<0.30 \mu \mathrm{g} / \mathrm{L}$ or $>3.0 \mu \mathrm{g} / \mathrm{L}$ were excluded based on WHO and ACGIH guidelines for valid urine samples (American Conference of Governmental Industrial Hygienists (ACGIH), 2012; World Health Organization (WHO), 1996). Reference materials used for calibration of the ICP-MS were obtained from Ultra Scientific Analytical Solutions (Kingston, $\mathrm{RI})$. The laboratory performing the assay is the provincial centre for metals analysis of biological samples and participates in multiple external quality assurance schemes including those of the College of American Pathologists (CAP) and the Institut national de santé publique du Québec (INSPQ).

Statistical Analysis

Urinary metal concentrations were corrected for creatinine concentration. The minimum detectable concentration noted on clinical reports was used as the limit of quantification (LOQ, ug/L). Values less than the LOQ were substituted prior to creatinine correction using the $\beta$ - 
substitution method that estimates a substitution value based on the data above the LOQ (Ganser and Hewett, 2010); substitution values were estimated for each metal independently based 107 active tradeswomen who provided a urine sample (substitution values: Cd 0.067 ug/L; Cr 0.069 ug/L; Co 0.071 ug/L; Cu 4.45 ug/L; Mn 0.310 ug/L; Ni 0.105 ug/L; Zn 9.95 ug/L.) Arithmetic and geometric means, together with median and range, were computed for comparison with published sources.

A 95th percentile for the general population was estimated for the seven metals of interest using previously published literature from the Canadian and US populations (US Centres for Disease Control and Prevention, 2013; Health Canada, 2010; Paschal et al., 1998), giving preference to Canadian values where these were available. The percentage of subjects exceeding the population 95th percentile was calculated for comparison with the expected value of 5\%. Urinary metal concentrations in male welders were extracted from six earlier publications for comparison with female results (Weiss et al., 2013; Ellingsen et al., 2006; Mukherjee et al., 2004; Scheepers et al., 2008; Verschoor et al., 1988; Luo et al., 2009).

Self-reported tasks and types of welding on the last day welding at work were used in analysis as binary factors (reported: yes/no). Age at completing the exposure questionnaire and reported smoking habit at that time (ever/never smoker) were considered as potential confounders.

Principal component analysis (PCA) was used to reduce the number of dimensions of exposure to be considered. It allowed multiple correlated urinary metals to be incorporated into a smaller number of uncorrelated variables. Components with an eigenvalue greater than one were retained. Multiple regression models were used to investigate the relation of welding tasks/types to natural log transformed, creatinine-corrected, concentrations. Confounders related $(\mathrm{p}<0.05)$ to 
outcomes in bivariate analysis were included in the regression model for that outcome only. All statistical analyses were completed in SPSS (SPSS v. 20, Chicago, IL)

\section{RESULTS}

A total of 132 of those registered as a welding apprentice were invited to supply a urine sample and $103(78 \%)$ complied, sending back a sample by mail. Of these 56 had been welding in the 6 months before completing their exposure questionnaire. Nine had a creatinine concentration outside of the recommended range $(>0.3-\leq 3.0 \mathrm{~g} / \mathrm{L})$ and two, on closer inspection, had been registered as sheet metal, rather than welding, apprentices. The analyses reported here are thus based on 45 women, 44 welders and one steam fitter. Not all women recorded the date of sample collection but where data were available, the mean time between completion of the exposure questionnaire and urine sample collection was 22 days. The mean interval between sample collection and receipt at the university after transport through the mail was 7 days. The median age of subjects at the time of completing the exposure questionnaire was 26.8 years (range 17.352.1). Twenty nine percent (13 women) were current smokers, 12 were ex-smokers.

Among the seven metals of interest, the number of samples with concentrations below the level of quantification ranged from zero (manganese, zinc) to 17 (37.8\%) for nickel (Table 1). This table also shows arithmetic means and means of the natural log transformed values used in the principal component and regression analyses. A highly significant Pearson correlation between transformed values was seen for cobalt and nickel $(\mathrm{r}=0.58$; $\mathrm{p}<0.001)$ and lower correlation was observed both for chromium and nickel $(\mathrm{r}=0.35 ; \mathrm{p}<0.02)$ and chromium and cadmium $(\mathrm{r}=0.29$; 
$\mathrm{p}<0.05)$. Manganese was weakly correlated with copper $(\mathrm{r}=0.28 ; \mathrm{p}=0.06)$ and cobalt $(\mathrm{r}=0.27$;

$\mathrm{p}=0.08$ ). In this study group zinc was unrelated to any of the other metals.

These correlations are reflected in the principal component analysis (Table 2). The first component is most heavily weighted with nickel and cobalt with only a small contribution from zinc. The second contrasts manganese and cobalt with zinc and the third copper and manganese with nickel and cobalt.

Tasks and types of welding are shown in Table 3. Multiple tasks and multiple types of welding were commonly reported for the last day at work: $17(38 \%)$ women reported more than one task and $15(33 \%)$ more than one type of welding. The most common task was fabrication, reported by $29(64 \%)$ women, but more than half of these reported also some other task. SMAW was the most common form of welding, reported by 28 (62\%) women, with nearly $40 \%$ (11 women) also reporting other types of welding on the last day of welding. The mean component scores for the six tasks and five types of welding did not show any significant differences despite large number the large number of comparisons made (results not shown).

To account for multiple tasks and types of welding reported by the same woman and to explore effects on individual urinary contaminants, a series of multiple regression analyses were carried out with natural log transformed concentrations as the dependent variables. Potential confounders included smoking and age. These were found to be related only to urinary cadmium concentration, with arithmetic means of $0.35 \mathrm{ug} / \mathrm{g}$ creatinine in those who had ever smoked and $0.19 \mathrm{ug} / \mathrm{g}$ creatinine in those who had not $(\mathrm{p}<0.01)$. The Pearson correlation between age and cadmium concentration was $0.40(\mathrm{p}<0.01)$. The standardized regression coefficients (adjusted for smoking and age for cadmium only) from these analyses of task are shown in Table 1 of the 
Supplementary Material. The only task/metal regression coefficient that approached significance was higher chromium in those who reported repair work ( $\beta=0.2995 \%$ CI -0.03 to 1.52 ; $\mathrm{p}=0.06$ ). Similarly in models including all types of welding, the only effect seen was with cadmium (Supplementary Material, Table 2) which had a significant negative coefficient for GMAW ( $\beta=-0.5195 \%$ CI -1.09 to $-0.17: \mathrm{p}<0.01)$ after adjustment for smoking and age. The nine women reporting repair work had an arithmetic mean for chromium of $1.3 \mathrm{ug} / \mathrm{g}$ creatinine compared with $0.56 \mathrm{ug} / \mathrm{g}$ creatinine for those who did not report this task. The 22 women reporting GMAW had an arithmetic mean for cadmium of $0.20 \mathrm{ug} / \mathrm{g}$ creatinine; the mean for cadmium was $0.36 \mathrm{ug} / \mathrm{g}$ creatinine for the 23 who did not report GMAW.

The final step of the analysis was to compare distributions of urinary concentrations with those published elsewhere. Table 4 examines the proportion of women welders in which the concentration exceeds 95th percentiles reported in the general population. The proportions for manganese and chromium clearly exceed the expected 5\% with almost all welders (96\%) exceeding the 95th percentile for manganese. Less than 5\% of women exceeded the 95th percentiles for copper, nickel and zinc; no welders exceeded the 95th percentiles for either cadmium or cobalt. The data available on male welders was limited for copper (Table 5), with concentrations available for a sample of 20 boiler makers (Mukherjee et al., 2004) and 68 spot and arc welders (Luo et al., 2009). The geometric mean in the women welders (10.96 ug/g creatinine) was three times that of the boiler makers (3.94 ug/g creatinine) and the highest value (158 ug/g creatinine) greatly exceeding the range in the male welders (Mukherjee et al., 2004; Luo et al., 2009). For cadmium, chromium, cobalt and zinc, the women's concentrations were rather similar to those for the men, but for nickel the geometric mean ( $0.54 \mathrm{ug} / \mathrm{g}$ creatinine) was very much lower than that reported for a mixed group of male welders in Russia (Ellingsen et al., 
2006) and for the boiler makers (Mukherjee et al., 2004). The highest female nickel concentration $(5.74 \mathrm{ug} / \mathrm{g}$ creatinine) was far below that of the Chinese male welders (Luo et al., 2009). The geometric mean for manganese in the female welders was, in contrast, higher by a factor of 10 for the Russian welders and two-fold for the boilermakers (Ellingsen et al., 2006; Mukherjee et al., 2004). The highest recorded value (11.33 ug/g creatinine) for women was appreciably higher than that recorded for the Russian welders (Ellingsen et al., 2006).

\section{DISCUSSION}

The analysis of metal concentrations in urine samples from female welders was instructive in that it demonstrated that these women were more exposed, at least to manganese and chromium, than the general population and suggested that exposure to manganese, as reflected in urine concentrations, might be higher in female than male welders. Although there is, as yet, no evidence of reproductive effects resulting from manganese exposure in female workers, high levels of manganese from drinking water were associated with infant death in one study (Hafeman et al., 2007) but not in a second (Cherry et al., 2010). Evidence of neurotoxicity in the worker is reflected in the new ACGIH TLV for manganese, including that in welding fume (American Conference of Governmental Industrial Hygienists, 2013). As such, any suggestion of high exposures in women welders justifies further investigation to identify preventive measures. However, the limitations of the study described here are appreciable and would not all be avoided by simply increasing the sample size.

First, given the wide distribution of workers even within a single province (Alberta) and the resulting practical difficulties of monitoring breathing zone concentrations, there is little 
alternative to using urine samples as a biomarker reflection of dose. Pilot work suggested that mailing of urine samples did not affect concentrations (Cherry et al., 2011). Of the seven metals considered only three, cadmium, chromium and cobalt have ACGIH BEI, all specified for measurement in urine at the end of the shift at end of work week. The biological assessment values published for workers in Germany suggest that nickel may also be assessed from urine samples collected after several exposed shifts but, as a carcinogen, no guideline concentration is suggested (Commission for the Investigation of Health Hazards of Chemical Compounds in the Work Area, 2013). Lauwerys and Hoet (2001) consider that urine may be the appropriate medium for monitoring of zinc but that there is insufficient data to suggest whether urine (or blood) might be an appropriate biological monitor for copper. Manganese is mainly eliminated in feces with only about $1 \%$ of the absorbed dose excreted in urine, but the portion in urine has some correlation with air concentration (Lauwerys and Hoet, 2001).

None of the samples we received approached the BEI for cadmium, chromium or cobalt. We do not know exactly when the samples were collected in relation to the work week but, with the pattern of work for many welders in Alberta including long spells in work camps in the oil fields, we suspect that the questionnaires may have been completed, and urine samples collected, during breaks of several days away from work. A further study of this group would be improved by collecting information about timing more precisely, encouraging end of work week sampling, or collecting repeated urine samples on individuals as suggested recently by Baker et al. (2014). Second, although we chose to ask the welders about a specific day at work (the most recent on which they welded) this day may have been atypical. We know also that sometimes many days elapsed between describing that work day and collecting the sample. While this would be unimportant if every work day were very similar, that is unlikely to be the case for many of these 
women working in, for example, oil and gas extraction. Again this limitation would be lessened if women were to be persuaded to collect the sample immediately on completing the questionnaire: collection in real time (while the interviewer or website paused) might theoretically be ideal, but would not be practical. Third, although very detailed information was collected about each welding activity and materials used, including duration, ventilation and use of PPE, only binary variables on the basic tasks/welding types have been used in this analysis. The metal exposure of welders is likely to be largely affected by the metal content of the consumable (welding rod or wire) being used, and the base metal being welded and this will be addressed in further analyses including more welders. Finally, we compared urine concentrations in women with those of men whose welding jobs may have been very different, for geographic or cultural reasons. Recognizing this, we are initiating a cohort of male welders within the same province, WHAT-MEN, in part to collect urine samples in a larger and more comparable group of male and female welders with metal concentrations quantified in the same laboratory for both groups.

The analysis of metals, either individually or through component scores, very largely failed to identify tasks or welding types associated with high exposures. Review of the literature found rather few studies in which urine concentrations correlated with differences in task or work practices. An early paper by Stridsklev et al. (1993) showed higher urinary levels of chromium and nickel in stainless steel welders using SMAW who did not wear respiratory protection (Stridsklev et al., 1993). A later paper by this group concludes that levels of chromium and nickel were lower in GTAW welders than SMAW (Stridsklev et al., 2004). In the Weldox study, urinary chromium was highest with SMAW and blood manganese lower for GTAW than for flux-cored arc welding (Pesch et al., 2012). With repeated exposures, however, little cross-shift 
change in urinary concentrations may be observed for any of these metals, suggesting that changes in work patterns may not be readily detected (Botta et al., 2006). It is perhaps not surprising, given the mix of tasks and welding types reported in the present study, and the possibility of intervening exposures between task reporting and urine collection, that no clear pattern was seen.

The use of component scores, as adopted here, is particularly valuable when many highly correlated determinants are each significantly related to a dependent variable, and when specific tasks have 'signature' patterns of exposure (Meijster et al., 2004; Schilmann et al., 2010). Although theoretically promising, the fact that none of the urinary concentrations was strongly related to task meant that the extraction of components was less likely to provide useful insights.

This is the first study to report on the urinary metal concentrations in a population of exclusively female welders. Although the results may, for some metals, represent little more than background variation without clear relationship to welding, for certain metals, specifically manganese and chromium, urinary concentrations were elevated, almost certainly reflecting work in this trade. The higher manganese in female than male welders may, in part, reflect the lower iron found in women of childbearing age, reflecting blood loss through menstruation. Finley et al. (1994) observed that manganese levels were higher among women than men, and subsequently (Finley, 1999) demonstrated that manganese absorption from food was significantly increased among women with low levels of serum ferritin. However, this relationship has not been demonstrated in relation to inhalation or skin exposure, routes we expect to be more important in the occupational setting. Iron status was not measured in the current study. 
The existence and continued funding of the WHAT-ME cohort and the associated WHAT-MEN study now getting underway, provides a unique opportunity to examine more closely the welding tasks and materials associated with ill-health and reproductive outcomes in female (and male) welders, in addition to the ongoing urinary bio-monitoring of metal exposures best suited to this method. As the demographics of the workforce change, it is important to consider whether sex differences in exposure, dose, or response exist, and what (if any) impact these differences may have on the hazards and associated risk faced by workers.

Funding: This study was funded by WorkSafeBC in association with Alberta Workplace Health and Safety

Conflicts of Interest: None of the authors has declared any conflict of interest. 


\section{REFERENCES}

American Conference of Governmental Industrial Hygienists. 2013. Manganese, elemental and inorganic compounds. .

American Conference of Governmental Industrial Hygienists (ACGIH). 2012. 2012 TLVs and BEIs threshold limit values for chemical substances and physical agents.

Baker MG, Simpson CD, Sheppard L, Stover B, Morton J, Cocker J, Seixas N. Variance components of short-term biomarkers of manganese exposure in an inception cohort of welding trainees. J Trace Elem Med Biol. 2014 May 23. [Epub ahead of print]

Botta C, Iarmarcovai G, Chaspoul F, Sari-Minodier I, Pompili J, Orsiere T, Berge-Lefranc JL, Botta A, Gallice P, De Meo M. 2006. Assessment of occupational exposure to welding fumes by inductively coupled plasma-mass spectroscopy and by the alkaline comet assay. Environ Mol Mutagen 47(4):284-295.

Cherry NM, Burstyn I, Nish K, Cembrowski G, Manning C, Beach J. 2011. Females welding and the unborn child. http://www.worksafebc.com/contact_us/research/research_results/res_60_10_1220.asp.

Cherry N, Shaik K, McDonald C, Chowdhury Z. 2010. Manganese, arsenic, and infant mortality in Bangladesh: An ecological analysis. Arch Environ Occup Health 65(3):148-153.

Commission for the Investigation of Health Hazards of Chemical Compounds in the Work Area. 2013. Report 49: List of MAK and BAT values 2013. 2nd ed. ed. Hoboken: John Wiley \& Sons.

Ellingsen DG, Dubeikovskaya L, Dahl K, Chashchin M, Chashchin V, Zibarev E, Thomassen Y. 2006. Air exposure assessment and biological monitoring of manganese and other major welding fume components in welders. J Environ Monit 8(10):1078-1086.

Finley JW. 1999. Manganese absorption and retention by young women is associated with serum ferritin concentration. Am J Clin Nutr 70(1):37-43.

Finley JW, Johnson PE, Johnson LK. 1994. Sex affects manganese absorption and retention by humans from a diet adequate in manganese. Am J Clin Nutr 60(6):949-955.

Ganser GH, Hewett P. 2010. An accurate substitution method for analyzing censored data. J Occup Environ Hyg 7(4):233-244.

Hafeman D, Factor-Litvak P, Cheng Z, van Geen A, Ahsan H. 2007. Association between manganese exposure through drinking water and infant mortality in Bangladesh. Environ Health Perspect 115(7):1107-1112.

Health Canada. 2010. Report on human biomonitoring of environmental chemicals in Canada results of the Canadian Health Measures Survey Cycle 1 (2007-2009). http://www.hcsc.gc.ca/ewh-semt/alt_formats/hecs-sesc/pdf/pubs/contaminants/chms-ecms/report-rapporteng.pdf. 
Lauwerys RR, Hoet P. 2001. Industrial chemical exposure: Guidelines for biological monitoring. 3rd ed. ed. Boca Raton, FL: Lewis Publishers. .

Li GJ, Zhang LL, Lu L, Wu P, Zheng W. 2004. Occupational exposure to welding fume among welders: Alterations of manganese, iron, zinc, copper, and lead in body fluids and the oxidative stress status. J Occup Environ Med 46(3):241-248.

Luo JC, Hsu KH, Shen WS. 2009. Inflammatory responses and oxidative stress from metal fume exposure in automobile welders. J Occup Environ Med 51(1):95-103.

Meijster T, Burstyn I, Van Wendel De Joode B, Posthumus MA, Kromhout H. 2004. Evaluating exposures to complex mixtures of chemicals during a new production process in the plastics industry. Ann Occup Hyg 48(6):499-507.

Mukherjee S, Palmer LJ, Kim JY, Aeschliman DB, Houk RS, Woodin MA, Christiani DC. 2004. Smoking status and occupational exposure affects oxidative DNA injury in boilermakers exposed to metal fume and residual oil fly ash. Cancer Epidemiol Biomarkers Prev 13(3):454460.

Paschal DC, Ting BG, Morrow JC, Pirkle JL, Jackson RJ, Sampson EJ, Miller DT, Caldwell KL. 1998. Trace metals in urine of United States residents: Reference range concentrations. Environ Res 76(1):53-59.

Pesch B, Weiss T, Kendzia B, Henry J, Lehnert M, Lotz A, Heinze E, Kafferlein HU, Van Gelder R, Berges M, Hahn JU, Mattenklott M, Punkenburg E, Hartwig A, Bruning T. 2012. Levels and predictors of airborne and internal exposure to manganese and iron among welders. $\mathrm{J}$ Expo Sci Environ Epidemiol 22(3):291-298.

Scheepers PT, Heussen GA, Peer PG, Verbist K, Anzion R, Willems J. 2008. Characterisation of exposure to total and hexavalent chromium of welders using biological monitoring. Toxicol Lett 178(3):185-190.

Schilmann A, Lacasana M, Blanco-Munoz J, Aguilar-Garduno C, Salinas-Rodriguez A, FloresAldana M, Cebrian ME. 2010. Identifying pesticide use patterns among flower growers to assess occupational exposure to mixtures. Occup Environ Med 67(5):323-329.

Statistics Canada . 2013. Table 477-0053 - registered apprenticeship training, registrations , by age groups, sex and major trade groups annual (number). 2013(July 18).

http://www5.statcan.gc.ca/cansim/

Stridsklev IC, Hemmingsen B, Karlsen JT, Schaller KH, Raithel HJ, Langard S. 1993. Biologic monitoring of chromium and nickel among stainless steel welders using the manual mental arc method. Int Arch Occup Environ Health 65(4):209-219.

Stridsklev IC, Schaller KH, Langard S. 2004. Monitoring of chromium and nickel in biological fluids of stainless steel welders using the flux-cored-wire (FCW) welding method. Int Arch Occup Environ Health 77(8):587-591. 
Trevisan A, Nicoletto G, Maso S, Grandesso G, Odynets A, Secondin L. 1994. Biological monitoring of cadmium exposure: Reliability of spot urine samples. Int Arch Occup Environ Health 65(6):373-375.

US Centers for Disease Control and Prevention. 2013. Fourth Report on Human Exposure to Environmental Chemicals, Updated Tables (September, 2013). Atlanta, GA: U.S. Department of Health and Human Services, Centers for Disease Control and Prevention.

http://www.cdc.gov/exposurereport/

Verschoor MA, Bragt PC, Herber RF, Zielhuis RL, Zwennis WC. 1988. Renal function of chrome-plating workers and welders. Int Arch Occup Environ Health 60(1):67-70.

Weiss T, Pesch B, Lotz A, Gutwinski E, Van Gelder R, Punkenburg E, Kendzia B, Gawrych K, Lehnert M, Heinze E, Hartwig A, Kaefferlein HU, Hahn J, Bruening T, WELDOX Grp. 2013.

Levels and predictors of airborne and internal exposure to chromium and nickel among weldersresults of the WELDOX study. Int J Hyg Environ Health 216(2):175-183.

World Health Organization (WHO). 1996. Biological monitoring of chemical exposure in the workplace Volume 1. Geneva: World Health Organization.

http://whqlibdoc.who.int/hq/1996/WHO_HPR_OCH_96.1.pdf 
Table 1: Urinary concentrations of metals from women welders $(\mathrm{N}=45)$

\begin{tabular}{|l|c|c|c|c|c|c|c|}
\hline \multirow{2}{*}{$\begin{array}{c}\text { Urinary } \\
\text { metal }\end{array}$} & \multirow{2}{*}{$\begin{array}{c}\text { Limit of } \\
\text { quantification } \\
\text { (LOQ) } \mathrm{ug} / \mathrm{L}\end{array}$} & $\begin{array}{c}\mathrm{n}< \\
\text { LOQ }\end{array}$ & \multicolumn{5}{|c|}{ Concentrations (ug/g of creatinine) with beta substitution } \\
\cline { 5 - 8 } Cadmium & 0.11 & 7 & 0.28 & 0.20 & $0.05-0.93$ & 0.23 & 1.88 \\
\hline Chromium & 0.15 & 8 & 0.72 & 1.44 & $0.03-7.71$ & 0.37 & 2.83 \\
\hline Cobalt & 0.12 & 3 & 0.47 & 0.33 & $0.04-1.44$ & 0.36 & 2.14 \\
\hline Copper & 6.36 & 2 & 14.65 & 22.01 & $6.67-158.08$ & 11.82 & 1.57 \\
\hline Manganese & 0.44 & 0 & 2.39 & 1.94 & $0.60-11.33$ & 1.92 & 1.90 \\
\hline Nickel & 0.29 & 17 & 1.21 & 1.39 & $0.04-5.74$ & 0.54 & 4.22 \\
\hline Zinc & 19.62 & 0 & 262.06 & 134.04 & $76.12-621.34$ & 230.44 & 1.67 \\
\hline
\end{tabular}


Table 2: Component loading scores for the principal component model (using natural log transformation of creatinine corrected urinary concentration)

\begin{tabular}{|l|c|c|c|}
\hline \multirow{2}{*}{} & \multicolumn{3}{|c|}{ Component } \\
\cline { 2 - 4 } & 1 & 2 & 3 \\
\hline $\begin{array}{l}\text { \% of variance } \\
\text { explained } \\
\text { Urinary metal }\end{array}$ & 29.7 & 18.3 & 16.4 \\
Cadmium & 0.52 & 0.19 & -0.10 \\
Chromium & 0.61 & 0.29 & 0.21 \\
Cobalt & 0.65 & -0.42 & -0.42 \\
Copper & 0.45 & 0.19 & 0.69 \\
Manganese & 0.40 & -0.59 & 0.54 \\
Nickel & 0.78 & 0.01 & -0.40 \\
Zinc & 0.19 & 0.77 & -0.04 \\
\hline
\end{tabular}


Table 3: Tasks and types of welding reported on most recent day at work

\begin{tabular}{|l|c|}
\hline & $\mathrm{n}(\%)$ \\
\hline Task & $15(33)$ \\
\hline Pipe welding & $29(64)$ \\
\hline Fabrication & $9(20)$ \\
\hline Repair & $4(8.9)$ \\
\hline Construction & $5(11)$ \\
\hline Mixed & $6(13)$ \\
\hline Other & \\
\hline Welding Type* & $28(62)$ \\
\hline SMAW & $22(49)$ \\
\hline GMAW & $6(13)$ \\
\hline GTAW & $0(0)$ \\
\hline PAW & $2(4.4)$ \\
\hline SAW & $2(4.4)$ \\
\hline Other & \\
\hline
\end{tabular}

*Abbreviations explained in methods section. 
Table 4: Proportion of women welders exceeding the general population $95^{\text {th }}$ percentile based on reference populations from the US and Canada

\begin{tabular}{|c|c|c|c|c|c|c|}
\hline & \multicolumn{3}{|c|}{$\begin{array}{l}\text { Reference populations } 95^{\text {th }} \text { percentile } \\
\text { (ug/g of creatinine) }\end{array}$} & \multirow{2}{*}{$\begin{array}{l}\text { Population } \\
95^{\text {th }} \\
\text { percentile } \\
\text { chosen } \\
\text { (ug/g of } \\
\text { creatinine) }\end{array}$} & \multicolumn{2}{|c|}{$\begin{array}{l}\text { Exceeded in WHAT-ME } \\
\text { welders }\end{array}$} \\
\hline & $1^{*}$ & $2^{*}$ & $3^{*}$ & & $\mathrm{n}$ & $\%$ \\
\hline Cadmium & 1.11 & 1.09 & - & 1.11 & 0 & - \\
\hline Chromium & - & - & 0.60 & 0.60 & 13 & 28.9 \\
\hline Cobalt & - & 1.64 & 4.72 & 1.64 & 0 & - \\
\hline Copper & 18.60 & - & - & 18.60 & 2 & 4.4 \\
\hline Manganese & 0.73 & - & & 0.73 & 43 & 95.6 \\
\hline Nickel & 4.59 & - & - & 4.59 & 2 & 4.4 \\
\hline Zinc & 575.71 & - & - & 575.71 & 1 & 1.1 \\
\hline
\end{tabular}

Reference populations were, in order of relevance:

1) Canadian Women: Canadian Health Measures Survey 2007-2009: women, ages 20-39 (Health Canada, 2010)

2) USA Women: National Health and Nutrition Examination Survey (NHANES) 20092010: women, all ages (US Centres for Disease Control and Prevention, 2013)

3) USA, Men and Women combined: NHANES 1988-1994: both sexes, all ages (Paschal et al., 1998). Only values where no significant difference between sexes was found were considered. 
Table 5: Metal concentrations (ug/g of creatinine) in this study and published male data on welders and boilermakers

\begin{tabular}{|c|c|c|c|c|c|c|c|c|c|c|c|c|}
\hline & \multicolumn{3}{|c|}{ Median } & \multicolumn{4}{|c|}{ Geometric mean } & \multicolumn{5}{|c|}{ Range } \\
\hline & Women & Men $1 *$ & $\operatorname{Men} 2 *$ & Women & Men $3^{*}$ & Men 4 & Men $5^{*}$ & $\begin{array}{l}\text { Women } \\
\text { highest }\end{array}$ & Men $1 *$ & Men $3^{*}$ & Men 4 & Men $6^{*}$ \\
\hline Cadmium & 0.23 & - & - & 0.23 & - & 0.22 & - & 0.93 & - & - & $0.02-2.6$ & - \\
\hline Chromium & 0.39 & 0.30 & $<1.35$ & 0.37 & 3 & 2.6 & 0.46 & 7.71 & $<0.1-3.7$ & $1-62$ & $0.14-51$ & - \\
\hline Cobalt & 0.38 & - & - & 0.36 & - & 0.25 & - & 1.44 & - & - & $0.03-11$ & - \\
\hline Copper & 10.96 & - & - & 11.80 & - & - & 3.94 & 158.08 & - & - & - & $0.2-19.3$ \\
\hline Manganese & 1.86 & - & - & 1.91 & - & 0.17 & 0.95 & 11.33 & - & - & $0.03-5.5$ & - \\
\hline Nickel & 0.75 & - & $<2.56$ & 0.54 & - & 4.0 & 8.45 & 5.74 & - & - & $0.68-28$ & $1.1-36.4$ \\
\hline Zinc & 213.38 & - & - & 231.13 & - & 224 & - & 621.34 & - & - & $3.4-2390$ & $3.8-114.4$ \\
\hline
\end{tabular}

post shift values

Men 1: 53 welders Netherlands (Scheepers et al. 2008)

Men 2: 241 welders Germany (Weiss et al. 2013)

Men 3: 45 stainless steel workers Netherlands (Verschoor et al. 1988)

Men 4: 96 welders Russia (Ellingsen et al. 2006)

Men 5: 20 boilermakers USA (Mukherjee et al. 2004)

Men 6: 68 full time welders China (Luo et al. 2009) 